
distributed under the terms of the Creative Commons Attribution licence (http://creativecommons.org/licenses/by/4.0/), which permits unrestricted re-use, distribution, and reproduction in any medium, provided the original work is properly cited. ORIGINAL RESEARCH doi:10.1017/ipm.2021.64

\title{
Psychiatric court reports and diversion outcomes in a remand prison over three years
}

\author{
Kezanne Tong ${ }^{1,8}$ (D) , Damian Smith ${ }^{2,8}$, Christopher Mohan ${ }^{3}$, Philip Hickey ${ }^{4,8}$, Enda Taylor ${ }^{4,8}$, Lisa McLoughlin ${ }^{2}$, \\ Harry G. Kennedy ${ }^{5,6}$ (D) and Conor $\mathrm{O}^{\prime} \mathrm{Neill}^{2,7,8, *}$ \\ ${ }^{1}$ Senior Registrar, National Forensic Mental Health Service, Central Mental Hospital, Dundrum, Dublin, Ireland \\ ${ }^{2}$ Consultant Forensic Psychiatrist, National Forensic Mental Health Service, Central Mental Hospital, Dundrum, Dublin, Ireland \\ ${ }^{3}$ Registrar, National Forensic Mental Health Service, Central Mental Hospital, Dundrum, Dublin, Ireland \\ ${ }^{4}$ Forensic Community Mental Health Nurse, National Forensic Mental Health Service, Central Mental Hospital, Dundrum, Dublin, Ireland \\ ${ }^{5}$ Consultant Forensic Psychiatrist and Executive Clinical Director, National Forensic Mental Health Service, Central Mental Hospital, Dundrum, Dublin, Ireland \\ ${ }^{6}$ Clinical Professor in Forensic Psychiatry, Department of Psychiatry, Trinity College Dublin, Dublin, Ireland \\ ${ }^{7}$ Clinical Senior Lecturer, Department of Psychiatry, Trinity College Dublin, Dublin, Ireland \\ 8 Prison Inreach and Court Liaison Service, Cloverhill Prison, Dublin, Ireland
}

Objectives: There has been a notable increase in requests for psychiatric reports from District Courts for persons remanded to Ireland's main remand prison, Cloverhill. We aimed to identify if reports were prepared for persons with severe mental illness and if they led to therapeutic benefits such as diversion to healthcare. Measures of equitability between Cloverhill and other District Courts were explored.

Methods: For District Court-requested reports completed by the Prison Inreach and Court Liaison Service (PICLS) at Cloverhill Prison from 2015 to 2017, we recorded clinical variables and therapeutic outcomes such as diversion to inpatient psychiatric settings.

Results: Of 236 cases, over half were diverted to inpatient or outpatient psychiatric care. One-third of remand episodes were admitted to a psychiatric hospital, mainly in non-forensic settings. Nearly two-thirds had major mental illness, mainly schizophrenia and related conditions. Almost half had active psychosis. Cases in Cloverhill District Court and other District Courts were similarly likely to have active psychosis ( $47 \%$ overall) and hospital admission ( $33 \%$ overall). Voluntary reports were more likely to identify active psychosis, with over $90 \%$ diverted to inpatient or outpatient community treatment settings.

Conclusions: This is the first large scale study of diversion outcomes following requests for psychiatric advice from District Courts in Ireland. Requests were mainly appropriate. Over half led to diversion from the criminal justice system to healthcare settings. There is a need for a complementary network of diversion initiatives at every stage of the criminal justice system to effectively divert mentally ill individuals to appropriate settings at the earliest possible stage.

Received 16 September 2020; Revised 04 August 2021; Accepted 19 August 2021

Key words: Court diversion, court liaison, Prison Inreach and Court Liaison Service, psychiatric court reports, therapeutic jurisprudence.

\section{Introduction}

'Therapeutic jurisprudence' involves the use of the law to achieve therapeutic outcomes (Winick, 2002). Psychiatric court diversion is broadly defined as the transfer of persons with mental illness from the criminal justice system to locations where they may receive appropriate treatment. This may be followed by a maintenance phase in which the court may monitor progress based on feedback from mental healthcare providers and other supports. Diversion and liaison services

*Address for correspondence: Conor O'Neill, Consultant Forensic Psychiatrist, National Forensic Mental Health Service, Central Mental Hospital, Dundrum, Dublin, Ireland; Prison Inreach and Court Liaison Service, Cloverhill Prison, Dublin, Ireland; Clinical Senior Lecturer, Department of Psychiatry, Trinity College Dublin, Dublin, Ireland.

(Email: oneillc50@tcd.ie) should be available at all points where people with major mental illness come in contact with the criminal justice system, including at point of arrest, in courts and in remand settings, to provide therapeutic alternatives, while taking into account risk assessment and public safety concerns (Birmingham, 2001; World Health Organization, 2005; Birmingham et al. 2017). Highquality and timely psychiatric court reports may assist the Court in identifying these individuals and providing answers to questions that arise regarding diversion to healthcare.

Mental Health Court diversion and liaison services should be a feature of any modern mental health service and criminal justice service. It is important to demonstrate that such services are accessible, equitable and effective, taking into account the perspectives of relevant stakeholders including patients, carers, courts, 
police and other external agencies. Methodology to demonstrate such effectiveness may vary depending on the perspective (e.g. that of judges requesting psychiatric assessments for persons appearing in court with apparent mental illness). It is particularly important that existing services be evaluated, to determine whether such services should be discontinued, modified or expanded.

The 2006 blueprint for Irish mental health services 'A Vision for Change' (Department of Health, 2006: 136) stated: 'every person with serious mental health problems coming into contact with the forensic system should be afforded the right of mental health care in the non-forensic mental health services unless there are cogent and legal reasons why this should not be done'. 'Sharing the Vision', the 2020 blueprint for mental health care in Ireland stated that 'Ireland does not yet have a specific policy to provide for court diversion or community treatment' (Department of Health, 2020: 51). Nonetheless, the mental health law in Ireland provides opportunities for diversion at the point of arrest and from prison settings. Firstly, Section 12 of the Mental Health Act 2001 (Department of Health and Children, 2001) enables An Garda Síochána (Irish police) to make applications for admission to local 'Approved Centres' at the point of arrest where a member of An Garda Síochána has 'reasonable grounds for believing that a person is suffering from a mental disorder and that because of the mental disorder there is a serious likelihood of the person causing immediate and serious harm to himself or herself or to other persons'. In practice, a general practitioner is then contacted to examine the person, but there may be very limited access to background information regarding the person's psychiatric history at the time.

Secondly, persons may be transferred from prisons to a single 'designated centre' [the Central Mental Hospital $(\mathrm{CMH})]$ under Section 15 of the Criminal Law (Insanity) Act 2006 (Department of Justice, Equality and Law Reform, 2006). This Act also enables courts to direct assessment at the 'designated centre' under Fitness to be Tried legislation (Section 4), to determine the presence or otherwise of a mental disorder at that time within the meaning of the Mental Health Act 2001. Courts do not have powers to direct transfer or admission to local general hospitals ('approved centres') which are not so designated. There is limited legislation providing specifically for diversion from courts to community services for minor offenders with major mental illness.

In Ireland, such diversion currently takes place mainly under the Bail Acts (criminal rather than civil legislation), with the person agreeing to be brought to an approved centre for assessment as to whether admission or other healthcare provision is required. The person typically later returns to court so the original offence can be dealt with, since diversion is not intended to be a 'get out of jail free card' (Greenberg $\&$ Nielsen, 2002). On rarer occasions, charges may be dropped, followed by applications for admission under the Mental Health Act 2001 in the usual way. The majority of diversions are to outpatient services.

Models for delivery of court diversion focus on different settings, including police stations, and through the courts either through 'on the day assessment' in court or following assessment in remand settings. There are many descriptions of local or regional approaches to diversion from courts and other settings (McInerney \& O'Neill, 2008; Davidson et al. 2017; Kane et al. 2018; Albalawi et al. 2019). Effective, equitable diversion services require service development at all stages of the criminal justice system including from police station, court and remand settings (Birmingham, 2001; Birmingham et al. 2017). Services exist to ensure that the right patient goes to the right place, with serious/high risk offenders going to secure settings and minor/low risk offenders with severe mental illnesses going to non-forensic community settings. Diversion services also provide a 'filter' to prevent inappropriate referrals from courts to local psychiatric services. In developing a court diversion system in Ireland, it was intended that multiple District Courts would be enabled to operate as mental health 'problem solving' courts, using a 'liaison' model.

Since 2006, the National Forensic Mental Health Service in Ireland has operated an intensive service in Cloverhill Prison, Dublin, Ireland's largest remand prison. The Prison Inreach and Court Liaison Service (PICLS) aims to identify newly received people on remand who have need of urgent psychiatric interventions. The PICLS team screens all remands from a 'catchment area' of courts serving a majority of the national population. Persons are first screened by prison nursing staff and general practitioners, with a 'second stage' screen by PICLS staff and approximately $15 \%$ receiving a detailed assessment by the PICLS team (McInerney et al. 2013; O'Neill et al. 2016). This allows for an equitable approach to identification. There is extensive liaison with local mental health services and other agencies from the point of committal, regarding appropriateness of diversion, where there is the possibility of bail or other noncustodial disposal for people with severe mental illness. Comprehensive reports are prepared for courts on request and submitted voluntarily when needed for those who are severely mentally ill. PICLS team members attend courts to advise and help arrange access to psychiatric healthcare in appropriate settings. The PICLS service model has been described in a service manual in multiple iterations (e.g. O’Neill et al. 2017) and its clinical outcomes 
in a series of papers, since the inception of the service in 2006 (O'Neill, 2006; McInerney \& O'Neill, 2008; McInerney et al. 2013; O'Neill et al. 2016; Georgiou \& Townsend, 2019). These outcome studies relate to all committals to Cloverhill since 2006, not just those for whom courts requested psychiatric reports.

Over time, there has been a marked increase in the number of psychiatric reports requested by District Courts from the PICLS service. The greatest activity is at Cloverhill District Court which is located adjacent to the remand prison, the source of most referrals and with attendance most days by PICLS team members. We aimed to explore whether this perceived increase in accessibility to our service has resulted in more inappropriate referrals of persons not suffering from major mental illness or requiring psychiatric intervention. Further we aimed to determine if the team's location at Cloverhill was associated with inequity in timescales for delivering psychiatric court reports and arranging diversion to healthcare, which may in turn have a negative impact on patient care.

\section{Aims}

We set out to answer the following four research questions in relation to patients for whom PICLS psychiatric court reports were requested by District Court Judges during the three years 2015-2017:

1. Did requests relate to the key target group (persons with severe mental illness)?

2. Did reports lead to therapeutic benefits for patients such as diversion to healthcare?

3. Was there equitability in terms of case-mix, time to delivery of reports and clinical outcomes between Cloverhill (the busiest court and source of most referrals) and other District Courts?

4. Did clinical profiles and outcomes of cases differ for cases in which the court requested a report and cases where a voluntary report was submitted following screening?

\section{Methods}

\section{Service setting}

Ireland had a population of 4.76 million as at April 2016 (the approximate midpoint of the study period), with $55 \%$ living in the province of Leinster, which includes Dublin, the only major conurbation (Central Statistics Office, 2017). In 2016, there were 2408 public and private psychiatric beds (Health Research Board, 2017) and a daily average of 3718 prisoners nationally (Irish Prison Service, 2017). The majority of remand prisoners were committed to Cloverhill Prison, which receives committals from a 'catchment area' covering the majority of the population of Ireland (Irish Prison Service, 2017). Three other mixed remand/sentenced prisons located in the west and southwest of Ireland accounted for most other male remands during the study period (Irish Prison Service, 2017). Over 95\% of committals nationally were male in 2016 (Irish Prison Service, 2017).

The District Court (equivalent to UK Magistrates Court) is organised on a local basis and tries summary offences attracting at most custodial offences of up to two years duration. The Circuit Court (equivalent to UK Crown Court) tries more serious offences that may attract longer sentences (indictable offences) before a jury. Ireland is divided into eight circuits for the purpose of this court. Where psychiatric court reports are requested for the High Court, they tend to be for the purpose of bail applications where this has been previously refused at lower court level. The Central Criminal Court is a criminal division of the High Court and tries the most serious offences including murder.

\section{Cases: Inclusion criteria}

A 'case' was defined as a remand episode for which one or more reports was completed by the Cloverhill PICLS team following request from a District Court Judge. Some individuals had more than one remand episode for which a report was requested. Where a person had more than one report during the same remand episode, these were treated as a single 'aggregated' report for the purpose of analysis.

Reasons for exclusion were voluntary reports, follow-up reports in the same remand episode; reports requested by Circuit Courts, High Courts, solicitors or the Office of the Director of Public Prosecutions (DPP) (Fig. 1). Of note, a psychiatric court report is usually required for diversion to community-based hospital settings, but is often not necessary to facilitate diversion to forensic hospital and community-based outpatient settings.

Follow-up reports mainly related to updated progress and fitness reports for persons for whom hospital admission had been recommended, but there was no bed identified or available. This included mainly persons awaiting beds in the $\mathrm{CMH}$ and for homeless people where there were delays in clarifying community catchment area responsibility.

While excluded from the main analysis, a smaller number of voluntarily-submitted 'on the day' reports relating to persons identified as seriously mentally ill on remand, while charged with minor offences, were separately described in terms of clinical symptoms and diversion outcomes (see Table 3 and supplementary material). 
4 K. Tong et al.

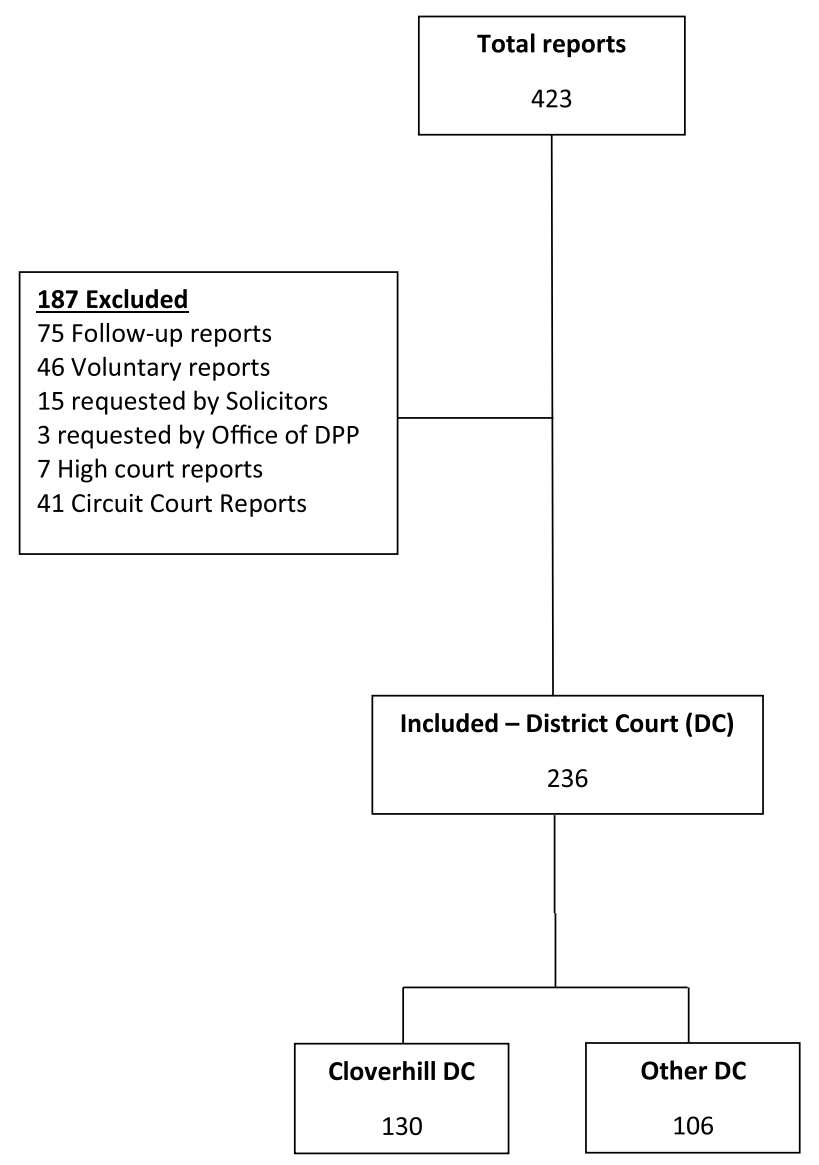

Fig. 1. Flow chart of psychiatric court reports included in the study.

\section{Data collection}

A list of court reports prepared by the PICLS service from 1 January 2015 to 31 December 2017 was held at the CMH. This list was cross-checked against a list maintained by the PICLS team based at Cloverhill Court and Prison. This second list included voluntary and other reports completed and was updated daily on working days. For each report, we recorded the type (e.g. District or Circuit Court) and location of the requesting court.

\section{Background factors}

Demographic variables recorded included gender and age at first report. Homelessness and offence types were recorded as binary variables. Homelessness was defined as not having regular accommodation, rough sleeping or residence in homeless shelters at the time of or during committal. Confirmation of housing status was based on serial team-based assessments and extensive collateral information, including input from the PICLS housing support worker.

Offence type was recorded as the most serious offence charged and classified as violent or non-violent.
A violent offence was defined as an act of physical violence on a person and included homicide, assault, robbery, aggravated robbery, contact sexual offences, false imprisonment, driving offences involving injury to others and arson where there was a possibility of injury to others.

\section{Historical clinical variables, current symptoms and primary ICD-10 diagnoses}

Clinical descriptors were also recorded as binary variables. These included: active psychotic symptoms identified following committal; lifetime history of psychotic symptoms; lifetime history of substance misuse difficulties; lifetime history of deliberate self-harm and lifetime history of contact with community mental health services. Primary ICD-10 diagnoses were clinical diagnoses made by the PICLS team, based on serial assessments and extensive collateral, including from previous treating mental health services.

\section{Clinical outcomes following reports}

Final clinical outcomes for persons after completion of reports included: admission to forensic hospital, admission to community psychiatric hospital; community 
Table 1. Psychiatric court reports completed by PICLS in the three years from 2015 to 2017 for each court type and location

\begin{tabular}{|c|c|c|c|c|c|c|}
\hline & \multicolumn{2}{|c|}{ All reports $(N=423)$} & \multicolumn{2}{|c|}{$\begin{array}{l}\text { District Court reports } \\
\text { excluding voluntary } \\
\text { reports }(N=236) \\
\end{array}$} & \multicolumn{2}{|c|}{$\begin{array}{l}\text { Circuit Court } \\
\text { reports }(N=41)\end{array}$} \\
\hline & $N$ & $\%$ & $N$ & $\%$ & $N$ & $\%$ \\
\hline \multicolumn{7}{|l|}{ Court type } \\
\hline District Court & 354 & 83.7 & 236 & 100 & - & - \\
\hline Circuit Court & 57 & 13.5 & - & - & 39 & 95.1 \\
\hline Central Criminal Court & 2 & 0.5 & - & - & 2 & 4.9 \\
\hline High Court & 10 & 2.4 & - & - & - & - \\
\hline Total & 423 & 100 & 236 & 100 & 41 & 100 \\
\hline \multicolumn{7}{|l|}{ Court location } \\
\hline Cloverhill Court Complex & 220 & 52 & 130 & 55.1 & - & - \\
\hline Criminal Courts of Justice & 70 & 16.5 & 24 & 10.2 & 24 & 58.5 \\
\hline Other locations & 133 & 31.5 & 82 & 34.7 & 17 & 41.5 \\
\hline Total & 423 & 100 & 236 & 100 & 41 & 100 \\
\hline \multicolumn{7}{|l|}{ Geographical location } \\
\hline Greater Dublin Area & 292 & 69 & 156 & 66.1 & 24 & 58.5 \\
\hline Other Leinster & 98 & 23.2 & 57 & 24.2 & 17 & 41.5 \\
\hline Connacht/Ulster & 20 & 4.7 & 15 & 6.4 & - & - \\
\hline Munster & 13 & 3.1 & 8 & 3.4 & - & - \\
\hline Total & 423 & $100 \%$ & 236 & $100 \%$ & 41 & $100 \%$ \\
\hline
\end{tabular}

outpatient treatment arrangements; discharge to prison primary care and prison transfer arrangements on sentencing.

\section{Time from request to delivery of reports}

Time to delivery of first report was measured in days from date of request in court to the date of court appearance with a report completed (rather than date of submission of report).

\section{Statistical analysis}

All data were entered using Microsoft Excel 2017. Following completion of data collection, data were exported to SPSS 24 for analysis. Binary categorical variables were analysed using Pearson Chi Square test. The mean and median of the time from request to delivery of court reports were calculated.

\section{Results}

\section{All reports: Court types and geographical locations (Table 1)}

In the three years 2015-2017, PICLS Cloverhill completed 423 psychiatric court reports. There were 120 reports completed in 2015, 145 in 2016 and 158 in 2017. Reports were completed on 277 individuals, remanded on 328 separate occasions. Of these 328 remand episodes, 29\% (95/328) were repeat reports relating to the same remand episode. These mainly related to updated progress reports for persons for whom hospital admission had been recommended, but there had been no bed made available. Of these, 74 had one follow-up report, 15 had two and six required three follow-up court reports during the same remand episode.

Of all 423 reports prepared by PICLS team members, $84 \%$ were prepared for District Courts, $14 \%$ for Circuit Courts and 2\% High Courts, and two reports were prepared for the Central Criminal Court. Reports were provided for 32 separate court locations. Overall, 69\% were for courts in the Dublin area, 23\% other Leinster, $5 \%$ Connacht/Ulster and 3\% for courts in Munster. Over half (52\%) were prepared for the Cloverhill court complex, $17 \%$ for courts in the Criminal Courts of Justice, Dublin and 32\% for other court locations.

\section{Psychiatric court reports excluded from analysis} (Fig. 1)

Excluded from analysis were 75 follow-up reports relating to the same remand episode. A further 46 reports had been submitted voluntarily by the PICLS team due to immediate concerns regarding mental health. Also excluded were: 48 reports for higher courts, 15 reports requested by solicitors and three requested by the Office of the DPP. A brief summary of clinical 
descriptors and outcomes for Voluntary reports and reports for Circuit Courts is provided in 'supplementary material' online.

Following this process, 236 District Court-directed reports or aggregated reports were included for analysis (Table 1). Of 236 first reports prepared for District Courts for a given remand episode, 130 (55\%) were prepared for Cloverhill District Court and 106 (45\%) for other District Courts (26 other Dublin Courts, 57 other Leinster and 23 from other regions).

\section{Key findings}

1. Did requests relate to the key target group (persons with severe mental illness)? (Table 2)

\section{Background factors}

All cases were male. Mean age at time of completion of first reports requested was 34 years (s.D. 10.7, range 1876 years). Approximately half (48\%) were homeless. Less than one quarter $(23 \%)$ were charged with violent offences.

\section{Historical clinical variables}

Over three-quarters $(78 \%)$ cases were patients previously known to community mental health services. Over half $(54 \%)$ had a lifetime history of psychosis, and $90 \%$ a history of substance misuse problems. Almost half ( $48 \%$ ) had a history of self-harm.

Active psychotic symptoms

Almost half (47\%) had displayed active psychotic symptoms (delusions, hallucinations or thought disorder) in the course of the remand episode.

\section{Primary clinical ICD-10 diagnosis}

Two-thirds $(64 \%)$ had a primary clinical diagnosis of ICD-10 major mental illness. The most common diagnosis $(41 \%)$ was of schizophrenia, schizotypal and delusional disorders (ICD-10 F20-29). For 16/236 (6.8\%) patients for whom District Court reports were requested, the primary diagnosis was of an intellectual disability. One-third (36\%) had a primary diagnosis of substance use disorder, personality disorder or no mental illness.

\section{Did reports lead to therapeutic benefits for patients such as diversion to healthcare? (Table 2)}

One-third ( $33 \%$ ) of the 236 cases were admitted to a psychiatric hospital. Overall, 67 (28\%) were admitted to 'approved' acute psychiatric units in the community and $11(5 \%)$ to the 'designated' forensic hospital $(\mathrm{CMH})$. For 51 cases $(22 \%)$, community outpatient follow-up was arranged. The remaining 107 cases were referred to other prison mental health teams on transfer or sentencing or discharged to prison primary care and/or addiction services.

3. Was there equitability in terms of case-mix, time to delivery of reports and clinical outcomes between Cloverhill and other District Courts? (Table 2)

Of the 236 District Court reports, 130 (55\%) were prepared for Cloverhill District Court and 106 (45\%) for other District Courts.

Background factors

Cloverhill District Court cases were older (mean age $35 v$. 32 years, $t=2.62, p=0.01$ ) and more likely to be homeless $\left(59 \%\right.$ v. 33\%, $\left.X^{2}=16.1, p<0.001\right)$. The proportion charged with violent offences did not differ significantly between Cloverhill and and other District Courts $\left(20 \%\right.$ v. $\left.26 \%, X^{2}=1.00, p=0.32\right)$.

\section{Historical clinical variables}

Cloverhill cases were more likely to have a lifetime history of psychosis than other District Courts $(60 \%$ v. $\left.46 \%, X^{2}=4.5, p=0.04\right)$. Cases at Cloverhill and other District Courts did not differ significantly in terms of previous contact with community mental health services, history of self-harm and history of substance misuse problems.

\section{Active psychotic symptoms}

The proportion of cases in Cloverhill with active symptoms of psychosis during the remand episode was similar to that in other District Courts $(49 \%$ v. $45 \%$, $\left.X^{2}=0.24, p=0.63\right)$.

\section{Primary ICD-10 diagnosis}

Regarding diagnostic groupings as listed in Table 2, there were no significant differences between Cloverhill cases and those in other District Courts.

Time from request to delivery of reports

Median time from date of request to delivery of first report on court date was 13 days (interquartile range 8-16 days). The mean time was 13.9 days (s.D. 9.5, 95\% confidence interval 12.6-15.1)

Median time from request to delivery of first reports was similar in Cloverhill and other District Courts at 13 days. Mean times to delivery were also similar (13.5 days $v$. 14.3 days, $t=0.59, p=0.56$ ).

\section{Clinical outcomes following reports}

Similar proportions of Cloverhill cases and those in other District Courts were admitted to hospitals (34\% v. $\left.32 \%, X^{2}=0.08, p=0.77\right)$. Proportions admitted to general and forensic hospitals did not differ significantly. Proportions referred for community outpatient 
Table 2. Comparison of background factors, clinical characteristics and clinical outcomes for 236 District Court-requested psychiatric reports completed by PICLS Cloverhill during 2015-2017, with a comparison of those prepared for Cloverhill District Court and other District Courts

\begin{tabular}{|c|c|c|c|c|c|c|c|c|}
\hline \multirow[b]{2}{*}{ Variables } & \multicolumn{2}{|c|}{ All District Court reports $(N=236)$} & \multicolumn{2}{|c|}{ Cloverhill District Court reports $(N=130)$} & \multicolumn{2}{|c|}{ Other District Court reports $(N=106)$} & \multirow{2}{*}{$\begin{array}{l}\text { Statistical test of } \\
\text { difference }\end{array}$} & \multirow[b]{2}{*}{$p$-Value } \\
\hline & $N(\%)$ & Mean (s.D.) & $N(\%)$ & Mean (s.D.) & $N(\%)$ & Mean (s.D.) & & \\
\hline \multicolumn{9}{|l|}{ Background factors } \\
\hline Sex - Male & $236(100.0)$ & & $130 / 130(100 \%)$ & & $106 / 106(100 \%)$ & & & \\
\hline Age & & $\begin{array}{l}33.5 \text { years } \\
\text { (s.D. 10.7) }\end{array}$ & & 35.1 years (s.D. 10.4) & & 31.5 years (S.D. 10.8$)$ & $t=2.62$ & $0.01^{*}$ \\
\hline Homeless $^{b}$ & $112(47.5 \%)$ & & $77(59.2 \%)$ & & $35(33.0 \%)$ & & $\chi^{2}=16.09$ & $<0.001^{*}$ \\
\hline Violent offence $^{\mathrm{a}}$ & $53(22.5 \%)$ & & $26(20.0 \%)$ & & $27(25.5 \%)$ & & $x^{2}=1.00$ & 0.32 \\
\hline \multicolumn{9}{|l|}{ Historical clinical variables } \\
\hline Lifetime history of contact with community mental health services & $183(77.5 \%)$ & & $104(80.0 \%)$ & & $79(74.5 \%)$ & & $x^{2}=1.00$ & 0.32 \\
\hline Lifetime history of psychosis & $127(53.8 \%)$ & & $78(60.0 \%)$ & & $49(46.2 \%)$ & & $x^{2}=4.46$ & $0.04^{*}$ \\
\hline Lifetime history of self-harm & $114(48.3 \%)$ & & $60(46.2 \%)$ & & $54(50.9 \%)$ & & $x^{2}=0.54$ & 0.46 \\
\hline Lifetime history of substance misuse problems & $213(90.3 \%)$ & & $116(89.2 \%)$ & & $97(91.5 \%)$ & & $x^{2}=0.35$ & 0.56 \\
\hline \multicolumn{9}{|l|}{ Current symptoms and primary ICD-10 diagnosis } \\
\hline Active psychosis during remand period & $111(47.0 \%)$ & & $63(48.5 \%)$ & & $48(45.3 \%)$ & & $x^{2}=0.24$ & 0.63 \\
\hline $\begin{array}{l}\text { Any ICD-10 Axis I diagnosis other than personality disorder, sub- } \\
\text { stance misuse or no mental illness }\end{array}$ & $152(64.4 \%)$ & & $88(67.7 \%)$ & & $64(60.4 \%)$ & & $x^{2}=1.36$ & 0.24 \\
\hline ICD-10 Diagnosis F20-29 (schizophreniform disorders) & $97(41.1 \%)$ & & $56(43.1 \%)$ & & $41(38.7 \%)$ & & $\chi^{2}=0.466$ & 0.50 \\
\hline ICD F30-39 (affective disorder) & $25(10.6 \%)$ & & $13(10.0 \%)$ & & $12(11.3 \%)$ & & $x^{2}=0.11$ & 0.74 \\
\hline Substance use disorder (as primary diagnosis) & $26(11.0 \%)$ & & $13(10.0 \%)$ & & $13(12.3 \%)$ & & $x^{2}=0.31$ & 0.58 \\
\hline Personality disorder (as primary diagnosis) & $28(11.9 \%)$ & & $17(13.1 \%)$ & & $11(10.4 \%)$ & & $x^{2}=0.41$ & 0.52 \\
\hline No mental illness & $30(12.7 \%)$ & & $12(9.2 \%)$ & & $18(17.0 \%)$ & & $x^{2}=3.16$ & 0.08 \\
\hline \multicolumn{9}{|l|}{ Clinical outcomes following reports } \\
\hline Any psychiatric admission & $78(33.1 \%)$ & & $44(33.9 \%)$ & & $34(32.1 \%)$ & & $x^{2}=0.08$ & 0.77 \\
\hline Forensic admission & $11(4.7 \%)$ & & $6(4.6 \%)$ & & $5(4.7 \%)$ & & $\chi^{2}=0.001$ & 0.97 \\
\hline General admission & $67(28.4 \%)$ & & $38(29.2 \%)$ & & $29(27.4 \%)$ & & $\chi^{2}=0.1$ & 0.76 \\
\hline Community outpatient clinic arranged & $51(21.6 \%)$ & & $28(21.5 \%)$ & & $23(21.7 \%)$ & & $\chi^{2}=0.001$ & 0.98 \\
\hline Referred to prison in-reach psychiatry team in receiving prison & $39(16.5 \%)$ & & $17(13.1 \%)$ & & $22(20.8 \%)$ & & $\chi^{2}=2.5$ & 0.11 \\
\hline Discharge to prison GP/addiction services & $68(28.8 \%)$ & & $41(31.5 \%)$ & & $27(25.5 \%)$ & & $\chi^{2}=1.05$ & 0.31 \\
\hline Time from request to delivery of first report (days) & & 13.9 (s.D. 9.5) & & 13.5 days (S.D. 7.1$)$ & & 14.3 days (s.D. 11.8) & $t=0.59 U=6593$ & 0.56 \\
\hline & & 13 (Median) & & 13 (Median) & & 13 (median) & $\begin{array}{c}\text { (Mann-Whitney } \\
\text { test) }\end{array}$ & \\
\hline
\end{tabular}

a Violent offence defined as an act of physical violence on a person and included homicide, assault, robbery, aggravated robbery, contact sexual offences, false imprisonment, driving offences involving injury to others and arson where there

was a possibility of injury to others.
${ }^{b}$ Homelessness defined as not having regular accommodation, rough sleeping or residence in homeless shelters at the time of or during committal. 
Table 3. Comparison of clinical descriptors and diversion outcomes for 45 reports submitted voluntarily to District Courts and 236 reports submitted following requests from District Courts 2015-2017

\begin{tabular}{lccccc}
\hline & $\begin{array}{c}\text { District } \\
\text { Court reports }\end{array}$ & $\begin{array}{c}\text { Voluntary } \\
\text { reports }\end{array}$ & $\begin{array}{c}95 \% \text { CI between } \\
\text { two proportions }\end{array}$ & $\chi^{2}$ test & $p$-Value \\
\hline Active psychosis & $111 / 236(47.0 \%)$ & $38 / 45(84.4 \%)$ & $21.09-52.91$ & 21.24 & $<0.001$ \\
Any mental illness & $152 / 236(64.4 \%)$ & $38 / 45(84.4 \%)$ & $5.03-34.97$ & 6.93 & 0.01 \\
Admission to Central Mental Hospital & $11 / 236(22.5 \%)$ & $0 / 45$ & $10.02-34.98$ & $\mathrm{n} / \mathrm{a}$ & $\mathrm{n} / \mathrm{a}$ \\
General inpatient diversion & $67 / 236(28.4 \%)$ & $31 / 45(68.9 \%)$ & $25.3-55.7$ & 27.29 & $<0.001$ \\
Outpatient diversion & $51 / 236(21.6 \%)$ & $11 / 45(24.4 \%)$ & $-10.42-16.02$ & 0.18 & 0.67 \\
Any diversion & $129 / 236(54.7 \%)$ & $42 / 45(93.3 \%)$ & $23.04-54.16$ & 23.73 & $<0.001$ \\
\hline
\end{tabular}

follow-up, discharged to the prison General Practitioner (GP) or transferred to other prisons did not differ significantly between Cloverhill cases and those in other District Courts.

\section{Did clinical profiles and outcomes of cases differ for court-requested reports compared with voluntary reports following screening? (Table 3)}

There were 46 voluntary reports submitted following screening, regarding patients identified as mentally ill and in need of treatment, but for whom there had been no request for a psychiatric report from the court. One was submitted to the High Court and the remaining 45 to District Courts. Of the 45 District Court voluntary reports, $84 \%$ related to persons identified as actively psychotic. Almost 70\% were diverted to community inpatient facilities (Approved Centres), with over 90\% being diverted to community inpatient or outpatient psychiatric settings (Table 3).

\section{Discussion}

\section{Summary of key findings}

Almost two-thirds (64\%) of the 236 cases for whom one or more reports were requested by District Court Judges had a major mental illness, with almost half (47\%) actively psychotic on assessment. One-third were admitted to a psychiatric hospital, with approximately six admissions to general hospitals for each forensic admission during the study period. One in five cases were diverted to outpatient community treatment settings.

Over half of all District Court reports included in our analysis were prepared for a single court, Cloverhill District Court, reflecting a centralised process which has developed over time. Referrals were similar to those in other District Courts in terms of clinical variables including diagnosis, prevalence of active psychotic symptoms and previous contact with local mental health services. Cloverhill defendants were significantly more likely to be homeless (60\%) compared with defendants in other courts combined. This may reflect the tendency of the homeless mentally ill to accumulate in major urban settings (Faris \& Dunham, 1939; Vassos et al. 2012).

The proportion subsequently diverted to community treatment settings was similar for both groups, suggesting that PICLS is enabling multiple courts to provide diversion functions in an equitable manner. This indicates that with the assistance of PICLS, all District Courts have the potential to act as a Mental Health Court, achieving therapeutic (diversion) alternatives to the criminal justice system for appropriate cases.

The mean time from request to delivery of reports (13.9 days) reflects the time between court appearances (persons being often remanded for two-week periods). This delay is regrettable, but does indicate that persons consequently diverted have major mental illness rather than the effects of acute intoxication or substance withdrawal. Provision of voluntary reports allows assessments and diversion outcomes to be submitted at an earlier stage. In certain clinically urgent situations, PICLS staff also travel to courts to provide voluntary verbal evidence to alert courts to serious mental health issues and diversion options 'on the day' without a formal report. Capacity to do this depends on levels of staffing for the service.

\section{Strengths and limitations}

This is the first large-scale study of court-directed psychiatric reports and associated diversion outcomes over a prolonged period in Ireland, and the first to examine the issue of equitability between District Courts in terms of service provision. This data differs from previous papers regarding PICLS patients which describe outcomes for all patients (including those for whom diversion was attained following voluntary reports or oral evidence alone), rather than the subgroup where a report was requested by a District Court Judge. 
This paper only describes persons who were identified in court by court workers as possibly mentally ill and for whom a psychiatric report was ordered by a District Court Judge. All were subsequently remanded into custody at Cloverhill Prison.

Longitudinal case descriptions for all PICLS patients, rather than this subgroup, are described in a separate series of multiyear studies since 2006 (McInerney et al. 2013; O'Neill et al. 2016). There are likely to be others who could have benefitted from liaison services and referral to mental health services who were not identified and who were released on the day, with an opportunity potentially missed to re-engage them with local mental health services.

This paper describes outcomes largely from the perspective of the service provided to District Courts. PICLS aims to provide a patient-centred service, intended to assist, advise and 'join up' all stakeholders including community mental health teams and other healthcare providers, An Garda Siochana, the courts, prisons, probation, housing services and other agencies, so that patients may access care in the most appropriate location, as early as possible.

The study was confined to males and to courts remanding to a single prison (albeit receiving a majority of male remands nationally). We found no published data describing diversion for other remand centres in Ireland other than Limerick Prison (Gulati et al. 2019). There is a functioning diversion service for female remands operating from the Dochas Centre in Dublin.

It is beyond the scope of this paper to provide a detailed recommendation for how a national strategy for diversion should be configured, including from remand prisons, courts and Garda Stations, with approaches to reduce the likelihood of repeat presentations through provision of community supports over time. There have been a series of working groups involving health, criminal justice and social care agencies over the past 15 years, which have attempted to address these issues.

\section{Conclusions}

Government policy expressed clearly in 'A Vision For Change', that forensic mental health services 'should be expanded and reconfigured so as to provide court diversion services and legislation should be devised to allow this to take place' (Department of Health, 2006: 140). The 2009 report of the Joint Working Group on Mental Health Services and the Police (involving the Mental Health Commission and An Garda Siochana) developed seven key recommendations, including implementation of existing policy, training for An Garda Siochana and development of District Court Diversion Services (Mental Health
Commission \& An Garda Siochana, 2009). The Interdepartmental Group to examine issues relating to people with mental illness who come in contact with the Criminal Justice System in their first interim report, recommended that 'An Garda Siochana implement a diversion policy .... for use in suitable cases when they come in contact with mental illness who may have committed a minor offence' (Government of Ireland, 2016: 4), and that relevant legislation, procedures and protocols be considered. The Group recommended 'that prison in-reach, court liaison and diversion services not be put on a formal statutory basis at this time' (Government of Ireland, 2016: 4).

The document, 'Change for the future $-A$ Vision for Change (AVFC) "refresh"', in December 2019, described the existing PICLS service, and stated that 'While Ireland does not yet have a specific policy to provide for court diversion .... the process can take place within the existing structures. The effectiveness of the (PICLS) service depends on on-going resourcing and access to facilities and services in the community .... The other recommendations of this "refresh" of AVFC may, if implemented, help in this context' (Department of Health, 2019: 70). The 2020 policy document, 'Sharing the Vision', included the recommendation that 'There should be ongoing resourcing of and support for diversion schemes where individuals with mental health difficulties are diverted from the criminal justice system at the earliest possible stage and have their needs met within community and/or nonforensic mental health settings' (Department of Health, 2020: 103).

At the time of writing (July 2021), a 'High Level Task Force on Mental Health and Addiction Challenges of persons interacting with the Criminal Justice System' had commenced work to address issues including development of a pilot Garda Diversion Project, which was in the advanced planning stage.

When implemented, Police Diversion Services have the potential to provide identification, support and diversion to appropriate health and social care at the earliest point in the pathway for people at times of crisis, many of whom will have mental health difficulties and related vulnerabilities. Almost one-third of admissions under the Mental Health Act 2001 in 2020 were initiated by An Garda Siochana (Mental Health Commission, 2021). For the present, however, there remain very high numbers of people with severe mental illness remanded to Irish prisons, many charged with minor offences (O'Neill et al. 2016).

There is scope for applying the PICLS model to all remand settings and related courts. There is scope for further enhancement and acceleration of the process of diversion by expanding PICLS team to enable daily staffing to certain of the busier key District Courts initially. The Irish Courts Service has already provided an 
office for the PICLS team in Ireland's busiest District Court at Cloverhill.

In a 2017 review of recent progress in diversion in England and Wales, despite developments in diversion services in recent years (in a jurisdiction where court and police diversion services are considerably more advanced than in Ireland), the authors found no evidence that prevalence of mental disorders reduced in the prison setting (Birmingham et al. 2017). The authors noted that 'We need less talk and more action .... We need a national network of diversion initiatives at all stages of the criminal justice system.... (requiring) evaluation through a robust programme of research' (Birmingham et al. 2017: 382). We contend that the remaining and already functioning components of diversion, such as diversion from remand prisons and through District Courts, also require adequate resourcing, particularly where robust outcome data over extended periods have been demonstrated for existing service models.

\section{Conflict of interest}

Reports commissioned by Courts are paid for by the Irish Courts Service, or via Legal Aid. Voluntary and repeat reports are provided pro-bono. The authors have no other conflict of interest to declare.

\section{Ethical standards statement}

The authors assert that all procedures contributing to this work comply with the ethical standards of the relevant national and institutional committee on human experimentation with the Helsinki Declaration of 1975, as revised in 2008. This project was approved by the National Forensic Mental Health Service Research and Ethics Committee.

\section{Financial support statement}

This research received no specific grant from any funding agency, commercial or not-for-profit sectors.

\section{Supplementary material}

To view supplementary material for this article, please visit https://doi.org/10.1017/ipm.2021.64

\section{References}

Albalawi O, Chowdhury NZ, Wand H, Allnutt S, Greenberg D, Adily A, Kariminia A, Schofield P, Sara G, Hanson S (2019). Court diversion for those with psychosis and its impact on re-offending rates: results from a longitudinal data-linkage study. BJPsych Open 5, e9.
Birmingham L (2001). Diversion from custody. Advances in Psychiatric Treatment 7, 198-207.

Birmingham L, Awonogun O, Ryland H (2017). Diversion from custody: an update. BJPsych Advances 23, 375-384.

Central Statistics Office (2017). Census 2016 Summary Results - Part 1. (https:/ /www.cso.ie/en/csolatestnews/ presspages/2017/census2016summaryresults-part1/). Accessed 11 August 2020.

Davidson F, Heffernan E, Greenberg D, Waterworth R, Burgess P (2017). Mental health and criminal charges: variation in diversion pathways in Australia. Psychiatry, Psychology and Law 24, 888-898.

Department of Health (2006). A Vision for Change: Report of the Expert Group on Mental Health Policy), p. 51. The Stationery Office.

Department of Health (2019). Change for the future - A vision for change 'refresh'. (https: / assets.gov.ie/78509/ baa20a18-490e-414a-bbe1-722ce2cacd53.pdf). Accessed 12 July 2021.

Department of Health (2020). Sharing the vision: A mental health policy for everyone.

Department of Health and Children (2001). The Mental Health Act 2001. The Stationery Office: Dublin.

Department of Justice (2021). Establishment of a high level taskforce to consider the mental health and addiction challenges of persons interacting with the criminal justice system. (http:/ / www.justice.ie/en/JELR/Pages/ PR21000071). Accessed 12 July 2021.

Department of Justice, Equality and Law Reform (2006). Criminal Law (Insanity) Act 2006. (http:/ /www. irishstatutebook.ie/eli/2006/act/11/enacted/en/html). Accessed 11 August 2020.

Faris REL, Dunham HW (1939). Mental disorders in urban areas: an ecological study of schizophrenia and other psychoses.

Georgiou M, Townsend K (2019). Quality Network for Prison Mental Health Services: reviewing the quality of mental health provision in prisons. The Journal of Forensic Psychiatry \& Psychology 30, 794-806.

Government of Ireland (2016). Interdepartmental group to examine issues relating to people with mental illness who come in contact with the criminal justice system - First interim report. (http://www.justice.ie/en/JELR/ interdepartmental-group-to-examine-issues-relating-topeople-with-mental-illness-who-come-in-contact-with-thecriminal-justice-system_first-interim-report.pdf/Files / interdepartmental-group-to-examine-issues-relating-topeople-with-mental-illness-who-come-in-contact-with-thecriminal-justice-system_first-interim-report.pdf). Accessed 12 July 2021.

Greenberg D, Nielsen B (2002). Court diversion in NSW for people with mental health problems and disorders. New South Wales Public Health Bulletin 13, 158-60.

Gulati G, Otuokpaikhian K, Crowley M, Pradeep V, Meagher D, Dunne CP (2019). Mental healthcare interfaces in a regional Irish prison. International Journal of Prisoner Health.

Health Research Board (2017). Activities of Irish Psychiatric Units and Hospitals 2016. (https://www.hrb. 
ie/data-collections-evidence/psychiatric-admissions-anddischarges/publications/publication/activities-of-irishpsychiatric-units-and-hospitals-2016/returnPage/1/). Accessed 11 August 2020.

Irish Prison Service (2017). Annual Report 2016. (http:/ / www.irishprisons.ie/wp-content/uploads/documents_ pdf/12631-IPS-annualreport-2016_Web.pdf). Accessed 11 August 2020.

Kane E, Evans E, Shokraneh F (2018). Effectiveness of current policing-related mental health interventions: a systematic review. Criminal Behaviour and Mental Health 28, 108-119.

McInerney C, O’Neill C (2008). Prison Psychiatric Inreach and Court Liaison Services in Ireland. Judicial Studies Institute Journal 147-158.

McInerney C, Davoren M, Flynn G, Mullins D, Fitzpatrick M, Caddow M, Caddow F, Quigley S, Black F, Kennedy HG, O'Neill C (2013). Implementing a court diversion and liaison scheme in a remand prison by systematic screening of new receptions: a 6 year participatory action research study of 20,084 consecutive male remands. International Journal of Mental Health Systems 7, 18.

Mental Health Commission, An Garda Siochana (2009). Report of Joint Working Group on Mental Health Services and the Police 2009. Mental Health Commision. (https://www.lenus.ie/handle/10147/111526). Accessed 11 July 2021.

Mental Health Commission (2021). Annual Report 2020. (https://www.mhcirl.ie/sites/default/files/2021-06/ MHC-Annual-Report-2020.pdf). Accessed 12 July 2021.

O'Neill C (2006). Liaison between criminal justice and psychiatric systems: diversion services. Irish Journal of Psychological Medicine 23, 87-88.

O'Neill C, McInerney C, Fitzpatrick M, Caddow M, O'Neill L (2017). PICLS Staff Manual. (http:/ / www.tara. tcd.ie/handle/2262/95128). Accessed 9 July 2021.

O'Neill C, Smith D, Caddow M, Duffy F, Hickey P, Fitzpatrick M, Caddow F, Cronin T, Joynt M, Azvee Z (2016). STRESS-testing clinical activity and outcomes for a combined prison in-reach and court liaison service: a 3-year observational study of 6177 consecutive male remands. International Journal of Mental Health Systems 10, 67.

Vassos E, Pedersen CB, Murray RM, Collier DA, Lewis CM (2012). Meta-analysis of the association of urbanicity with schizophrenia. Schizophrenia Bulletin 38, $1118-1123$.

Winick BJ (2002). Therapeutic jurisprudence and problem solving courts. Fordham Urban Law Journal 30, 1055.

World Health Organization (2005). WHO resource book on mental health, human rights and legislation: stop exclusion, dare to care. World Health Organization. 